\title{
Electrical stimulation of the hippocampus and perseveration in an exploratory maze'
}

\section{R. N. LEATON, Dartmouth College, Hanover, N. H. 03755}

Five rats with bipolar electrodes implanted unilaterally in the dorsal hippocampus were run in a T-maze with an exploratory incentive. Trials were given following the elicitation of afterdischarges by electrical stimulation and on alternate sets of days with no stimulation. There were no group differences in choice of the exploratory incentive between the stimulation and nonstimulation conditions, but two Ss chose the exploratory incentive more on trials following stimulation than on trials without stimulation while three Ss chose the exploratory incentive consistently less on trials following stimulation. All Ss perseverated more following stimulation. These results show marked similarities to results obtained in animals with hippocampal lesions.

Roberts, Dember, \& Brodwick (1962), Douglas \& Isaacson (1964), and Leaton (1967) have shown that hippocampal lesions in rats reduce the rate of spontaneous alternation. Leaton $(1965,1967)$ has shown that rats with hippocampal lesions perseverate more than controls in a $\mathrm{T}$-maze position discrimination reinforced by the opportunity for exploration. The present experiment was an attempt to replicate these behavioral effects of hippocampal lesions by using electrical stimulation of the dorsal hippocampus.

\section{Subjects}

Five experimentally naive male albino rats of SpragueDawley strain were approximately 60 days old at the time of surgery. Each $\mathrm{S}$ had bipolar electrodes implanted in the right dorsal hippocampus. Stereotaxic coordinates (DeGroot, 1959) were 3.8 anterior, 1.2 lateral, and +2.0 vertical. Histology showed that the placements closely approximated these coordinates which placed the electrode tips near the dentate gyrus in the dorsal hippocampus. The electrodes were .005 in. stainless steel wires, twisted tightly together and insulated except for the cross section of the tips. All Ss were allowed at least three weeks to recover from surgery before the beginning of the experiment. They were individually housed and maintained on ad lib food and water.

Apparatus

The Ss were tested in a T-maze identical, except for minor dimensional changes, to that described by Leaton (1965). The sides of the maze were $18 \mathrm{in}$. high. The top was open to allow Ss to run with stimulating leads attached, and the leads were suspended from a boom over the center of the maze. One of the large goal boxes contained various junk objects (exploratory box) and the other was the same size but empty (neutral box). Nonretrace doors were placed just beyond the choice point in each arm, and the goal boxes could not be seen from the choice point. White noise masked extraneous auditory stimuli.

Procedure

All Ss were given five days of pretraining following the same procedure used previously (Leaton, 1965). Entrances to both goal boxes were blocked. Stimulating leads were attached but stimulation was not applied. Following pretraining, stimulation thresholds for eliciting afterdischarges (ADs) were established. Stimulation was provided by a Grass S4 stimulator using a 60 pps square-wave with a $2 \mathrm{msec}$ pulse duration. Stimulation was applied for 5-10 sec and the EEG from the stimulating electrodes was monitored on a Grass Model 7 Polygraph immediately following the stimulation. Thresholds for ADs were usually around $100 \mu \mathrm{A}$.
Following threshold determination Ss were given eight trials a day for 18 days with the goal boxes in place. Three Ss had the exploratory box on the right and two had it on the left. On each trial $S$ was removed from the maze $1 \mathrm{~min}$ after entering a goal box. Noncorrection procedure was used and the intertrial interval was $5-10 \mathrm{~min}$. Trials 4 and 8 each day were forced trials which served to expose $S$ to his less preferred side for that day. On stimulation days Ss were stimulated for $5 \mathrm{sec}$ in the start box, the EEG was monitored, and the start door was opened allowing $S$ to make a choice. If no AD was elicited, the stimulation was repeated, with increased voltage if necessary, before the start door was opened. In most cases Ss remained in the start box or stem of the maze until the AD had subsided. The first four days were run following stimulation on each trial, then two days of nonstimulation were alternated with two days of stimulation for the remaining 14 days.

Results and Discussion

The first two stimulation days were not used in the analyses since they were considered learning days and not directly comparable to the other days. None of the conclusions would have been altered had they been included. The analyses were thus based upon the six daily free trials for the eight stimulation days and eight nonstimulation days for the same Ss.

There was no significant difference between the mean exploratory choices for the stimulation and nonstimulation conditions. For the eight stimulation days the mean number of daily exploratory choices was 3.1 ; for the nonstimulation days the mean was 3.8. However, there were differences in choice behavior between the conditions which were not reflected in these means. As shown in Table 1, three of the Ss made significantly fewer exploratory choices under the stimulation condition while two Ss made more exploratory choices following stimulation. This finding was not related to any correlation between the laterality of the stimulation electrodes and the position of the exploratory box, nor could the Ss be differentiated on histological examination of electrode placements. In addition, Ss perseverated more under the stimulation condition. This was shown by the fact that four of the five Ss ran all of their free trials to one side (the exploratory side for some Ss and the neutral side for others) on at least one of the eight stimulation days while no $S$ ever ran all trials to the same side in the nonstimulation condition ( $p<.025$, Fisher Exact Probability Test). These findings are almost identical to the results reported by Leaton (1965) in a similar situation following hippocampal lesions.

A perseveration score (the failure to alternate) was found for each $\mathrm{S}$ by summing the number of perseverative responses made on the first three and last three free trials of a day. By assigning an $S$ one point each time it went the same direction

Table 1

Mean Daily Exploratory Choices for Stimulation and Nonstimulation Days

\begin{tabular}{cccc}
\hline Rat No. & Stimulated & Nonstimulated & $\mathrm{p}^{*}$ \\
\hline 1 & 5.2 & 3.9 & $<.005$ \\
2 & 4.5 & 4.1 & $<.164$ \\
3 & 1.9 & 3.6 & $<.001$ \\
4 & 1.2 & 3.6 & $<.014$ \\
5 & 2.6 & 3.8 & $<.065$ \\
\hline
\end{tabular}

*Mann-Whitney U Test 
Table 2

Mean Daily Perseveration Score for Stimulation and Nonstimulation Days

\begin{tabular}{ccc}
\hline Rat No. & Stimulated & Nonstimulated \\
\hline 1 & 3.12 & 2.12 \\
2 & 2.38 & 1.50 \\
3 & 1.62 & 1.00 \\
4 & 3.12 & 1.12 \\
5 & 1.50 & 1.00 \\
\hline
\end{tabular}

as it did on the previous trial, perfect perseveration yielded a daily score of 4 . As shown in Table 2 , every $S$ had a higher perseveration score on trials following stimulation than on trials without stimulation. Under the stimulation condition the mean daily perseveration score was 2.35 ; while under the nonstimulation condition this mean was 1.35 . This difference is significant at $\mathrm{p}<.02(\mathrm{t}=3.77$, $\mathrm{df}=4$, two-tailed $)$. This finding is similar to previous findings showing that rats with hippocampal lesions alternate less than normals (Roberts, Dember, \& Brodwick, 1962; Douglas \& Isaacson, 1964; Leaton, 1967).

An incidental finding was that four of the five Ss often ejaculated in the maze during or following ADs. Related findings have been reported for the monkey (MacLean \& Ploog, 1962) and cat and rat (MacLean, 1957). The ADs became progressively longer and motor involvement more severe as training progressed making continuation beyond the number of days run practically impossible. Gutman, Costin, \& Bergmann (1962) reported similar prolongation of ADs following repeated hippocampal stimulation in the rabbit.

The present results show marked similarities to results achieved with bilateral hippocampal lesions. It is difficult to relate these results specifically to hippocampal function, since the ADs no doubt spread to many brain areas, and Ss usually showed motor seizures of varying length and severity following stimulation. In addition, many more parallels between the effects of ADs and hippocampal lesions would have to be found before an underlying functional relationship could be safely established. However, the present results show that the brain malfunctions for some period following the elicitation of an $A D$, and the marked similarities between the effects of ADs and hippocampal lesions suggest that the major focus of this malfunction may be the hippocampus.

\section{REFERENCES}

DeGROOT, J. The rat forebrain in stereotaxic coordinates. Verhandelignen Koninklijke Nederlandse Akademie van Wetenschappen, B. Naturkunde, 1959, 52, 1-40.

DOUGLAS, R. J. \& ISAACSON, R. L. Hippocampal lesions and activity. Psychonomic Science, 1964, 1, 187-188.

GUTMAN, J., COSTIN, A., \& BERGMANN, F. Constancy of hippocampal afterdischarge under various conditions of stimulation. Electroencephalography \& Clinical Neurophysiology, 1963, 15, 989-996.

LEATON, R. N. Exploratory behavior in rats with hippocampal lesions. Journal of Comparative \& Physiological Psychology, 1965, 59, 325-330.

LEATON, R. N. Patterns of behavior of hippocampal lesioned rats in an exploratory motivated situation. Psychological Reports, 1967, 21, 153-159.

MacLEAN, P. D. Chemical and electrical stimulation of hippocampus in unrestrained animals. American Medical Association Archives of Neurology \& Psychiatry, 1957, 78, 128-142.

MacLEAN, P. D., \& PLOOG, D. W. Cerebral representation of penile erection. Journal of Neurophysiology, 1962, 25, 29-55.

ROBERTS, W. W., DEMBER, W. N., \& BRODWICK, M. Alternation and exploration in rats with hippocampal lesions. Journal of Comparative \& Physiological Psychology, 1962, 55, 695-700.

NOTE

1. This research was supported by Grant HD 01850-03 from the National Institute of Child Health and Human Development. Thanks are due to James Newton for his assistance. 